\title{
I Like Me If You Like Me: On the Interpersonal Modulation and Regulation of Preadolescents' State Self-Esteem
}

\author{
Sander Thomaes, Albert Reijntjes, \\ and Bram Orobio de Castro \\ Utrecht University
}

Astrid Poorthuis

Utrecht University

\author{
Brad J. Bushman \\ University of Michigan \& VU University \\ Amsterdam
}

\author{
Michael J. Telch \\ University of Texas at Austin
}

\begin{abstract}
This experiment tested whether peer approval and disapproval experiences can cause immediate change in children's state self-esteem. Children's narcissistic traits and evaluator perceived popularity were examined as potential moderators. A total of 333 preadolescents $(M=10.8$ years) completed personal profiles on the Internet that were ostensibly judged by a jury consisting of popular and unpopular peers. Participants randomly received negative, neutral, or positive feedback from the jury. Next, they could examine the feedback that each individual judge gave them. As expected, peer disapproval decreased self-esteem, especially in children high in narcissism. In contrast, peer approval increased self-esteem. Moreover, disapproved children's self-esteem recovery was dependent on the extent to which they subsequently viewed positive feedback from popular judges. These findings support sociometer theory.
\end{abstract}

As social beings we live with our eyes upon our reflection, but have no assurance of the tranquillity of the waters in which we see it.

—Charles Horton Cooley, 1902, p. 247

Is children's self-esteem dependent on how much they are liked by others? Classical theory holds that throughout development, children gradually come to internalize the opinions that others hold of them into more or less stable patterns of self-esteem (Cooley, 1902; Mead, 1934). Supporting this view, research shows that children's trait self-esteem (i.e., their enduring appraisal of value as a person) tends to reflect the cumulative appraisals of others in the past (e.g., Boivin, Hymel, \& Hodges, 2001; Cole, Jacquez, \& Maschman, 2001; Felson \& Zielinski, 1989; Ladd \& Troop-Gordon, 2003; but see Salmivalli \& Isaacs, 2005, for an exception). Another classical view holds that self-esteem is open to temporary fluctuations, and may wax and wane from moment to moment around an "average tone of self-feeling" (James, 1890). This latter, fluctuating type of self-esteem is called state self-esteem. Surprisingly little is known about the extent to which children's state self-esteem is sensitive to appraisals

Correspondence concerning this article should be addressed to Sander Thomaes, Department of Psychology, Utrecht University, P.O. Box 80.140, 3584 CS Utrecht, Netherlands. Electronic mail may be sent to s.thomaes@uu.nl. from others in the here and now. One possibility is that children's state self-esteem is only marginally reactive to current approval experiences, because these experiences are embedded in a long history of previous social interactions. Another possibility is that children's state self-esteem is profoundly reactive to current approval experiences, because these experiences are highly salient and meaningful in the present. This study uses an in vivo, experimental peer evaluation design to examine children's interpersonal state self-esteem reactivity in real time. In addition, it examines some theoretically relevant factors that may influence children's state self-esteem reactivity, namely narcissism and the perceived popularity of the person providing the appraisal.

\section{Interpersonal Appraisals and the Modulation of State Self-Esteem}

A pivotal contemporary account of interpersonal influences on self-esteem is found in sociometer theory (Leary \& Baumeister, 2000; Leary \& Downs, 1995). The basic assumption underlying the theory is that human beings possess a pervasive drive to

(C) 2010, Copyright the Author(s)

Journal Compilation @ 2010 , Society for Research in Child Development, Inc. All rights reserved. 0009-3920/2010/8103-0011 
be valued and accepted by others, a drive that evolved because our ancestors were more likely to survive and reproduce when they belonged to social groups (e.g., Ainsworth, 1989; Baumeister \& Leary, 1995; Leary \& Baumeister, 2000). Sociometer theory posits that self-esteem has evolved to (a) monitor how much one is valued and accepted by others, (b) evoke positive or negative feelings that signal change in others' approval, and (c) provide an outlook for how one may be approved in future interactions so that one can try to prevent possible disapproval. Thus, according to sociometer theory, interpersonally based changes in self-esteem are not just accidental by-products of positive or negative social interaction; they are central in enabling people to gain, maintain, and restore approval from others.

These functions of self-esteem are thought to operate in the short run and in the long run. Trait self-esteem is proposed to function as a long-term gauge that monitors the amount of approval obtained from others, instills enduring negative mood (e.g., depression) when one is disapproved by others, and motivates people to prevent longterm exclusion. State self-esteem is proposed to function as a short-term gauge that continuously monitors one's social environment and signals changes in immediate approval obtained from others. Social cues that connote approval or disapproval are assumed to modulate state self-esteem and trigger positive or negative affect (e.g., feelings of pride or shame), signaling that one's "relational

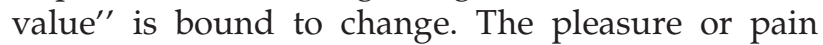
associated with state self-esteem fluctuations should motivate people to prevent exclusion in near future interactions. Research involving adult participants supports both the trait and state self-esteem postulates of sociometer theory. Trait self-esteem is a direct function of the extent to which adults generally feel approved by others (e.g., Leary, Cottrell, \& Phillips, 2001; Leary, Tambor, Terdal, \& Downs, 1995). Interpersonally based changes in trait selfesteem elicit longer term changes in negative mood and one's outlook for others' approval (e.g., Johnson, Meyer, Winett, \& Small, 2000). State selfesteem, in contrast, fluctuates according to how adults feel approved by others in the moment, and these fluctuations bring about short-term changes in negative mood and alert individuals to possible exclusion in the near future (e.g., Leary \& Downs, 1995; Leary, Haupt, Strausser, \& Chokel, 1998; Oosterwegel, Field, Hart, \& Anderson, 2001).

Empirical evidence for sociometer theory in children, however, is incomplete. That is, research in children has focused almost exclusively on longterm trait self-esteem and its interpersonal determinants (e.g., Boivin et al., 2001; Felson \& Zielinski, 1989; Ladd \& Troop-Gordon, 2003), and has largely neglected short-term state self-esteem and its interpersonal determinants. This seems unfortunate, because the psychological foundation for sensitivity to others' appraisals is laid early in life (Rubin, Bukowski, \& Parker, 2006). From middle childhood to preadolescence, two cognitive advances allow for interpersonal influences on self-esteem (Harter, 1999, 2006). First, improved perspective taking skills help preadolescents to better appreciate the appraisals of others. Second, the newfound ability to form higher order concepts allows preadolescents to make global self-evaluations (e.g., "I am satisfied with myself as a person") rather than more concrete and domain-specific self-evaluations (e.g., "I am good at soccer") that are typical for younger children. Because self-esteem is relatively unstable in preadolescence (Harter, 1999, 2006), one might expect ongoing appraisals of others to have a particular strong impact at this age. Appraisals of peers should be especially important because the peer group exerts an increasingly salient socializing function in preadolescence (Harter, Stocker, \& Robinson, 1996; Rubin et al., 2006; Rudolph, Caldwell, \& Conley, 2005).

A few studies have examined how children think their self-esteem depends on current peer appraisals (Burwell \& Shirk, 2006; Harter \& Whitesell, 2003; Harter et al., 1996; Rudolph et al., 2005). To our knowledge, however, only one study examined the self-esteem fluctuations that children actually experience following current peer appraisals, and the evidence from this single study was inconsistent with sociometer theory (Nesdale \& Lambert, 2007). Specifically, Nesdale and Lambert (2007) found that experimentally manipulated social rejection triggered negative affect (e.g., sadness, anxiety) but triggered no changes in children's self-esteem. Two limitations of Nesdale and Lambert's pioneering work should be noted, however. First, children were asked to role play a situation in which they were socially rejected; the social rejection was not played out in vivo. Although children can be responsive to role play (Rubin et al., 2006), their experience of pretended social encounters does not necessarily correspond well to their experience of actual social encounters (Robinson \& Clore, 2002). Second, a measure of trait self-esteem was used (sample item: "I think I can do things as well as anyone else" $\mathrm{e}^{\prime \prime}$, whereas sociometer theory predicts that current interpersonal appraisals influence 
children's state self-esteem (Leary, 1999; Leary et al., 1995). The first goal of the present experiment is to examine whether peer approval and disapproval modulate preadolescents' state self-esteem using an in vivo experimental peer evaluation manipulation.

\section{Individual Differences in the Interpersonal Modulation} of State Self-Esteem

According to sociometer theory, interpersonal self-esteem reactivity likely is a universal human trait. Of course, this is not to say there are no individual differences in the degree to which children's self-esteem is dependent on others' appraisals. Whereas some children's state self-esteem may be stable and relatively unaffected by current peer approval or disapproval experiences, other children's state self-esteem may be unstable and highly reactive to those experiences (Rudolph et al., 2005). The logic underlying sociometer theory implies that these individual differences should be a direct function of the importance children attach to being valued by others (see also Harter, 1999). Children who are greatly concerned with being valued by others should theoretically show pronounced interpersonal self-esteem reactivity.

An excessive need for external validation is a hallmark feature of the trait of narcissism. Whereas narcissism is a personality disorder in its extreme form (DSM-IV; American Psychiatric Association, 1994), most current psychological research (including our own) focuses on "normal narcissism," operationalized as a personality trait on which people in the general population vary (Morf \& Rhodewalt, 2001; Raskin \& Terry, 1988). "Normal narcissists" believe they are superior to others, yet at the same time they worry obsessively about what others think of them. They crave to be respected and admired by others, and tend to respond with intense emotions when they receive negative interpersonal feedback (Baumeister \& Vohs, 2001; Morf \& Rhodewalt, 2001; Rhodewalt \& Morf, 1998). Thus, narcissistic self-esteem is not only grandiose but is also markedly vulnerable to negative social experience (Morf \& Rhodewalt, 2001). Recent research found that individual differences in narcissistic traits can be meaningfully measured in children at least 8 years old (Thomaes, Stegge, Bushman, Olthof, \& Denissen, 2008) and that narcissistic children are emotionally reactive to negative social events (Thomaes, Bushman, Stegge, \& Olthof, 2008). The second goal of this experiment is to examine narcissism as a potential moderator of the interpersonal modulation of state self-esteem.
To establish discriminant validity, the moderating effect of narcissism is contrasted with the moderating effects of self-perceived social acceptance and peer-perceived social preference. These variables were chosen as controls because they are often considered indexes of social vulnerability (e.g., McElhaney, Antonishak, \& Allen, 2008; Patterson, Kupersmidt, \& Griesler, 1990) but do not involve an excessive need for external validation, which is presupposed to be a key determinant of individual differences in interpersonal self-esteem reactivity.

\section{Interpersonal Appraisals and the Regulation of State Self-Esteem}

Similar to other evolutionary-based monitoring mechanisms (e.g., hunger), self-esteem can reach certain critical low levels at which it is experienced as unpleasant, which then motivate behaviors intended to decrease the unpleasantness. Just as hunger feels bad and therefore motivates people to seek for food, lowered state self-esteem feels bad (i.e., triggers emotional distress) and therefore may motivate people to seek praise and positive feedback from others (Leary \& Baumeister, 2000). Theoretically, the more positive feedback that disapproved children with lowered state selfesteem obtain, the more their self-esteem should recover. We therefore propose that interpersonal appraisals are involved not only in the modulation of state self-esteem but also in the subsequent regulation of state self-esteem.

One might be inclined to assume that when disapproved children with lowered state self-esteem manage to subsequently acquire positive social feedback, they should invariably show pronounced increases in state self-esteem. Such a position may be oversimplified, however. From a young age, children attach differential importance to the appraisals that others hold of them, typically based on salient characteristics of others that cue group membership (Crick \& Dodge, 1994; McAninch, Manolis, Milich, \& Harris, 1993; Mrug \& Hoza, 2007). In elementary school, one important characteristic that children use to judge each other is perceived popularity (LaFontana \& Cillessen, 2002). Children who are perceived as popular exert a strong influence on their peers. They are on the top of the social hierarchy and to a large extent they determine the social rules according to which some children are valued and accepted whereas others are not (Adler \& Adler, 1998; Hawley, Little, \& Pasupathi, 2002; LaFontana \& Cillessen, 2002). Thus, if state self-esteem functions as a monitor of 
children's relational value, it should be particularly reactive to appraisals provided by perceived popular peers. The third goal of this experiment is to examine how peer appraisals influence the regulation of disapproved children's lowered state self-esteem. In particular, it will be examined whether positive appraisals from perceived popular peers have a stronger regulatory impact on state self-esteem than appraisals from unpopular peers.

\section{Present Study}

An experimental peer evaluation manipulation was used to examine the modulation and subsequent regulation of children's state self-esteem. Children's narcissistic traits and evaluator perceived popularity were examined as potential moderators of children's state self-esteem reactivity. Participants ranged in age from 8 to 12 years. This age group was chosen for four reasons. First, children this age have acquired the abilities to appreciate others' appraisals of them and to evaluate their global worth as a person (Harter, 1999, 2006). Second, children this age attach great importance to the opinions and appraisals of peers, much more so than younger children (Damon \& Hart, 1988; Harter, 1999, 2006; Rosenberg, 1979). Third, given their heightened concern with who is popular and who is not, children this age may be especially susceptible to the appraisals of perceived popular peers (Adler \& Adler, 1998; LaFontana \& Cillessen, 2002). Fourth, individual differences in narcissism can be reliably measured in children this age (Thomaes, Stegge, et al., 2008), who typically have outgrown the unrealistically positive self-views that are normative in younger children (Marsh, Craven, \& Debus, 1998).

Peer approval and disapproval were manipulated using the Survivor Game, which is an ostensible Internet contest shown to be highly effective at inducing credible peer approval and disapproval experiences in children (e.g., Reijntjes, Dekovic, Vermande, \& Telch, 2007; Reijntjes, Stegge, Meerum Terwogt, Kamphuis, \& Telch, 2006). Participants created a personal profile containing self-disclosing information as well as a photograph of themselves. By random assignment, they received negative social feedback (i.e., the lowest likability score), neutral social feedback (i.e., neither the lowest or the highest likability score), or positive social feedback (i.e., the highest likability score) on their profile from an Internet peer jury. In a subsequent self-esteem regulation period, participants could examine the feedback that each individual judge gave them. The individual judges provided either positive or negative feedback and were either perceived popular or unpopular. Thus, whereas the manipulated jury feedback was between subjects, the individual judges' feedback that participants subsequently viewed was within subjects. State self-esteem was assessed at baseline (T1), immediately after the manipulated jury feedback (T2), and immediately after viewing the individual judges' feedback (T3).

Based on sociometer theory, we predicted that from T1 to T2 children's state self-esteem would significantly decrease after disapproval, would not change after neutral feedback, and would significantly increase after approval. We predicted that children showing largest decreases in state selfesteem following disapproval would be high in narcissism (but would not differ from others in self-perceived social acceptance and peer-perceived social preference). Although narcissists may be more reactive to negative than to positive social events (Bushman \& Baumeister, 1998; Rhodewalt \& Morf, 1998), we also explored whether children showing largest increases in state self-esteem following approval were high in narcissism. Regarding the interpersonal regulation of state self-esteem, we predicted that positive feedback from perceived popular judges would have strong regulatory effects. Specifically, we predicted that disapproved children would show more state selfesteem recovery from T2 to T3 the more time they spent examining positive feedback from perceived popular judges (relative to positive feedback from perceived unpopular judges, or negative feedback). We also predicted that disapproved children would generally spend more time examining positive feedback from popular judges than other types of feedback.

\section{Method}

\section{Participants}

Participants were 333 preadolescents (49\% boys) who ranged in age from 8 to 12 years $(M=10.8$, $S D=0.9)$. They were recruited from 10 randomly selected public elementary schools serving lower (i.e., $4.2 \%$ below average Dutch income) to upper (i.e., 7.3\% above average Dutch income) middleclass communities in the Netherlands. The regions where the schools are located are representative of the Netherlands in terms of socioeconomic status, level of urbanization, and cultural or ethnical 
diversity. Most participants were ethnic Dutch (88\%); others mainly had mixed cultural or ethnical origins. All participants received informed parental consent (consent letters were sent home from schools, were signed and returned; consent rates ranged between schools from 68\% to 95\%; $M$ consent rate $=83 \%)$. Participants received a small gift (e.g., mechanical pens, markers) in exchange for their voluntary participation.

\section{Measures}

A few weeks prior to the experiment $(M=2$ weeks, range $=1-3$ weeks), participants completed measures of narcissism, self-perceived social acceptance, and a sociometric nomination procedure in their classes. Trained female psychology students provided instructions and answered questions. During the experiment, participants completed a measure of state self-esteem.

\section{Narcissism}

Narcissism was measured using the Dutch version of the 10-item Childhood Narcissism Scale (Thomaes, Stegge, et al., 2008). This psychometrically sound scale assesses grandiose views of self and inflated feelings of superiority and entitlement in children. Sample items include: "Without me, our class would be much less fun," "Kids like me deserve something extra," and "I often succeed in getting admiration." Items are rated along a 4-point scale ranging from 0 (not at all true) to 3 (completely true). Responses were summed, with higher scores indicating higher levels of narcissism (Cronbach's $\alpha=.79$ ).

Self-perceived social acceptance. Self-perceived social acceptance was measured using the Dutch version of the six-item social acceptance subscale of Harter's Self-Perception Profile for Children (1985; translated and validated by Veerman, Straathof, Treffers, Van den Bergh, \& ten Brink, 1997). This scale assesses children's evaluation of how well they can get along with their peers. Children first choose which of two contrasting descriptors describes themselves best (e.g., "Some kids would like to have a lot more friends, but other kids have as many friends as they want"). They then indicate whether the chosen descriptor is "sort of true" or "very true" for them. Items are rated along a 4point scale ranging from 0 to 3 . Responses were summed, with higher scores indicating higher levels of self-perceived social acceptance (Cronbach's $\alpha=.70$ ).
Peer-perceived social preference. Peer-perceived social preference was measured using sociometric nominations (Coie, Dodge, \& Coppotelli, 1982). Children nominated the children who they "like most" and "like least" in their classes. Following conventional procedures (e.g., Cillessen \& Mayeux, 2004), the number of nominations children received was standardized within each classroom. Then, the "like least" standardized score was substracted from the "like most" standardized score, and the resulting score was restandardized to create a measure of social preference.

State self-esteem. During the experiment, participants completed a six-item state self-esteem measure at baseline (T1; Cronbach's $\alpha=.68$ ), immediately after the manipulated jury feedback (T2; Cronbach's $\alpha=.80$ ), and immediately after viewing the individual judges' feedback (T3; Cronbach's $\alpha=.78$ ). The measure was modeled after standard measures of trait self-esteem (i.e., global self-worth subscale of Harter's SelfPerception Profile for Children, 1985; Rosenberg's Self-Esteem Scale, 1965), but assessed children's overall sense of worth right now, at the present time. Items reflected both a positive sense of self (e.g., "I feel good about who I am right now") and a negative sense of self (e.g., "I am dissatisfied with myself right now"; see the Appendix for all items). Items were rated along a 5-point scale ranging from 0 (not at all) to 4 (very much). Responses were summed with higher scores indicating higher levels of state self-esteem. In a recent study involving 405 children and young adolescents, our measure of state self-esteem was found to be strongly associatiated with a one-item pictorial measure of state self-esteem $(r=.71$, $p<.0001$; Thomaes, Bushman, Orobio de Castro, Cohen, \& Denissen, 2009). In addition, significant associations in the predicted direction were found between our measure of state self-esteem and trait measures of self-esteem (Harter, 1988), depression (Kovacs, 1981), and social anxiety (La Greca \& Stone, 1993).

\section{Experimental Procedure}

Participants were individually tested in a quiet room at their school by a female research assistant. First, they completed the T1 state self-esteem measure. Next, they were told they would be competing in a popularity contest on the Internet called Survivor Game (a bogus game created for research purposes). Participants were told they would play the game with four opponents of the 
same sex and age from different schools, and that all players would be evaluated by a panel of 16 peer judges. Each judge would give them a "likability score" between 0 (not at all likable) and 100 (extremely likable), and would also provide concrete written feedback. Participants were then told that we were interested in how the game "would make them feel" and what they "would think about" the judges' feedback. They were also informed that they were free to cease participation at any time they wanted and still receive their gift ( 2 children stopped before the game began). Next, participants completed a personal profile, so that the peer judges could ostensibly learn more about them. Questions concerned participants' hobbies, future occupation, things they like and dislike about themselves, how well they get along with other children, academic performance, and self-ratings on several personal traits (e.g., sense of humor, agreeableness, intelligence, trustworthiness). Participants were told that their personal profile and their picture would be posted on the Survivor Game Web page to be evaluated by the peer judges.

To enhance credibility, participants then viewed the personal profiles of their opponents, taken from actual profiles provided by participants in a different study (consent for using the profiles was obtained; names were changed). After viewing the last profile, a message appeared on screen indicating that the computer would now tally the judges' scores for each player. After a short waiting period, the names of the players with the highest and the lowest scores appeared in capital letters on screen. Participants were randomly assigned to one of three conditions. In the approval condition, the participant received the highest score, whereas one randomly chosen opponent received the lowest score. In the disapproval condition, the participant received the lowest score, whereas one randomly chosen opponent received the highest score. In the control condition, two randomly chosen opponents received the highest and lowest scores. Because participants allegedly scored in between they did not see their own name.

Immediately after receiving the jury results, participants completed the T2 state self-esteem measure. Next, an announcement appeared on screen informing participants that they would have $5 \mathrm{~min}$ to look over the feedback comments that the judges wrote about them. An overview screen appeared containing pictures of all 16 judges (8 boys and 8 girls). By clicking on the picture of a targeted judge, a new screen opened containing concrete feedback provided by that judge. The judges were counterbalanced to be either perceived popular or unpopular, and to provide either positive or negative feedback. The peer status of the judges was manipulated through the two key determinants of children's perceived popularity: their physical appearance and number of friends (LaFontana \& Cillessen, 2002). Popular judges were good looking and wrote they had "many friends," whereas unpopular judges were not good looking and wrote they had "few friends." In a pilot study, 10 children ( $M=$ 10.8 years) rated the judges' pictures (accompanied by a written statement about their number of friends) on a scale from 0 to 10 , and considered the popular judges as better looking $(M=7.6, S D=0.6$ vs. $M=3.9, S D=1.4)$ and as "probably more popular" $(M=7.7, S D=0.7$ vs. $M=3.9, S D=1.1$ ) than the unpopular judges, $t(14)=6.93, p<.0001, d=3.46$, and $t(14)=8.24$, $p<.0001, d=4.12$, respectively. The valence of the judges' feedback (positive or negative) was manipulated through the likability ratings and concrete feedback comments they provided. Positive judges provided favorable ratings ( $M$ likability score $=80$ of 100) and wrote only positive comments (e.g., "I would like to be friends with this person"). Negative judges provided unfavorable ratings ( $M$ likability score $=40$ of 100) and wrote only negative comments (e.g., "I would not like to be friends with this person"). Regardless of the experimental condition, all participants saw the same feedback from the 16 peer judges (i.e., 4 popular judges gave positive feedback, 4 popular judges gave negative feedback, 4 unpopular judges gave positive feedback, 4 unpopular judges gave negative feedback). The time (in seconds) that participants spent examining the four different types of feedback was recorded by the computer. Immediately after the feedback viewing period, participants completed the T3 state selfesteem measure.

Finally, participants were thoroughly debriefed. They were informed that the other players, the judges, and the evaluations they received were entirely fictitious. They were also informed about the study purposes, and the need for deception. They were assured that responses during the game would remain strictly confidential, and they were encouraged to ask questions or voice their concerns. To reduce possible lingering effects of the manipulation, participants were interviewed at length about a recent positive social experience in which they felt good. 


\section{Ethical Concerns}

Ensuring children's psychological well-being during the experiment was a priority of this research. Accordingly, recommendations for experiments involving child participants that require deception and a risk of emotional discomfort were strictly followed (see Hurley \& Underwood, 2002). Institutional Review Board approval was obtained, parents received a detailed consent letter describing the study, and children were preinformed about their rights to withdraw, were monitored for possible expressions of undue emotional distress, and were thoroughly debriefed. Research has shown that debriefings as described earlier are effective for preadolescent children; they typically understand how and why they were deceived, and what confidentiality entails (Hurley \& Underwood, 2002). In addition, preadolescents generally are well able to regulate their emotional responses, reducing the risk of prolonged emotional discomfort (Saarni, 1999). Our own work showed that children generally are positive about participation in the Survivor Game, and report no objections against the deception or other procedural details, both immediately after the experiment and 1 week later (Reijntjes et al., 2006, 2007).

\section{Results}

\section{Preliminary Analyses}

Table 1 presents the descriptive statistics for the study variables and the results of the preliminary analyses.

Sex differences and age. Analyses of variance (ANOVAs) showed that boys reported higher state self-esteem than girls at T2 $(p<.02)$ and T3 $(p<.02)$, but not at T1 $(p>.07)$. Sex differences in state self-esteem were not large $(d s<0.27)$. Children's age was not significantly related to any of the study variables $(p s>.08)$. Because there were no interactions involving sex or age, the data for boys and girls of different ages were combined for subsequent analyses.

\section{Equivalence of Experimental Conditions}

Analyses of variance showed that children's baseline state self-esteem, narcissism levels, selfperceived social acceptance, peer-perceived social

Table 1

Descriptive Statistics for the Study Variables and Results of the Preliminary Analyses

\begin{tabular}{|c|c|c|c|c|c|c|c|c|c|}
\hline \multirow[b]{2}{*}{ Variable } & \multirow{2}{*}{$\begin{array}{l}\text { Disapproval } \\
(N=108) \\
M(S D)\end{array}$} & \multirow{2}{*}{$\begin{array}{c}\begin{array}{c}\text { Control } \\
(N=115)\end{array} \\
M(S D)\end{array}$} & \multirow{2}{*}{$\begin{array}{c}\begin{array}{c}\text { Approval } \\
(N=110)\end{array} \\
M(S D)\end{array}$} & \multicolumn{2}{|c|}{$\begin{array}{l}\text { Equivalence } \\
\text { of conditions }\end{array}$} & \multicolumn{2}{|c|}{$\begin{array}{c}\text { Sex } \\
\text { differences }\end{array}$} & \multicolumn{2}{|c|}{ Age } \\
\hline & & & & $F(1,330)$ & $p$ value & $F(1,331)$ & $p$ value & $r$ & $p$ value \\
\hline \multicolumn{10}{|c|}{ State self-esteem (T1) } \\
\hline Total & $18.43(2.90)$ & $18.81(3.37)$ & $18.61(2.97)$ & 0.42 & $>.65$ & \multirow[t]{3}{*}{3.19} & \multirow[t]{3}{*}{$>.07$} & -.08 & $>.15$ \\
\hline Boys & $18.52(3.03)$ & $19.00(2.71)$ & $19.21(2.43)$ & 0.89 & $>.41$ & & & -.10 & $>.24$ \\
\hline Girls & $18.36(2.81)$ & $18.63(3.92)$ & $17.96(3.36)$ & 0.54 & $>.58$ & & & -.09 & $>.27$ \\
\hline \multicolumn{10}{|c|}{ Narcissism } \\
\hline Total & $8.59(5.24)$ & $8.76(4.83)$ & $8.70(4.42)$ & 0.01 & $>.98$ & \multirow[t]{3}{*}{3.37} & \multirow[t]{3}{*}{$>.06$} & .10 & $>.08$ \\
\hline Boys & $9.36(5.36)$ & $9.07(4.66)$ & $9.22(4.39)$ & 0.05 & $>.95$ & & & .01 & $>.90$ \\
\hline Girls & $8.08(5.17)$ & $8.38(4.99)$ & $8.26(4.52)$ & 0.06 & $>.94$ & & & .18 & $<.04$ \\
\hline \multicolumn{10}{|c|}{ Self-perceived social acceptance } \\
\hline Total & $12.34(3.07)$ & $12.37(3.16)$ & $11.83(3.41)$ & 0.97 & $>.37$ & \multirow[t]{3}{*}{0.98} & \multirow[t]{3}{*}{$>.32$} & .01 & $>.91$ \\
\hline Boys & $12.22(3.84)$ & $12.13(3.50)$ & $11.69(3.55)$ & 0.36 & $>.69$ & & & -.01 & $>.87$ \\
\hline Girls & $12.43(2.71)$ & $12.59(2.80)$ & $11.98(3.27)$ & 0.64 & $>.52$ & & & .04 & $>.58$ \\
\hline \multicolumn{10}{|c|}{ Peer-perceived social preference } \\
\hline Total & $0.09(0.83)$ & $0.02(1.09)$ & $-0.10(1.05)$ & 0.98 & $>.37$ & \multirow[t]{3}{*}{3.27} & \multirow[t]{3}{*}{$>.07$} & -.01 & $>.88$ \\
\hline Boys & $0.06(0.88)$ & $-0.13(1.30)$ & $-0.22(1.13)$ & 0.84 & $>.43$ & & & -.09 & $>.32$ \\
\hline Girls & $0.11(0.79)$ & $0.15(0.85)$ & $0.03(0.95)$ & 0.27 & $>.76$ & & & .12 & $>.16$ \\
\hline \multicolumn{10}{|c|}{ Age (years) } \\
\hline Total & $10.73(0.93)$ & $10.84(0.96)$ & $10.76(0.96)$ & 0.40 & $>.67$ & \multirow[t]{3}{*}{2.97} & \multirow[t]{3}{*}{$>.08$} & & \\
\hline Boys & $10.81(0.90)$ & 11.02 (1.06) & $10.81(0.89)$ & 0.76 & $>.46$ & & & & \\
\hline Girls & $10.66(0.96)$ & $10.69(0.83)$ & $10.72(1.02)$ & 0.05 & $>.95$ & & & & \\
\hline
\end{tabular}


preference, and age did not differ in the disapproval, control, and approval groups ( $p$ s > .37), indicating that random assignment to conditions was successful.

\section{Primary Analyses}

Interpersonal appraisals and the modulation of state self-esteem. Data were analyzed using a mixedmodel repeated measures analysis, with state self-esteem serving as the dependent variable, condition (disapproval, control, approval) serving as the between-subjects factor, and time (T1 vs. T2 state self-esteem assessment) serving as the withinsubjects factor. A significant Condition $\times$ Time interaction was found, $F(2,330)=40.25, p<.001$ (see Figure 1). As predicted, disapproved children displayed a sharp decrease in state self-esteem, $F(1, \quad 107)=44.62, \quad p<.0001, d=1.29$. Control children displayed no significant change in state self-esteem, $F(1,114)=2.10, p>.14, d=0.27$. Approved children displayed a sharp increase in state self-esteem, $F(1,109)=19.18, \quad p<.0001$, $d=0.84$. These findings show that peer approval and disapproval experiences cause immediate change in children's state self-esteem, consistent with sociometer theory.

Importantly, the effects reported earlier reflect normative, or "average" patterns of self-esteem reactivity. They provide no information on individual differences in self-esteem reactivity. Therefore, we computed a reliable change (RC) index (Christensen \& Mendoza, 1986) to distinguish children

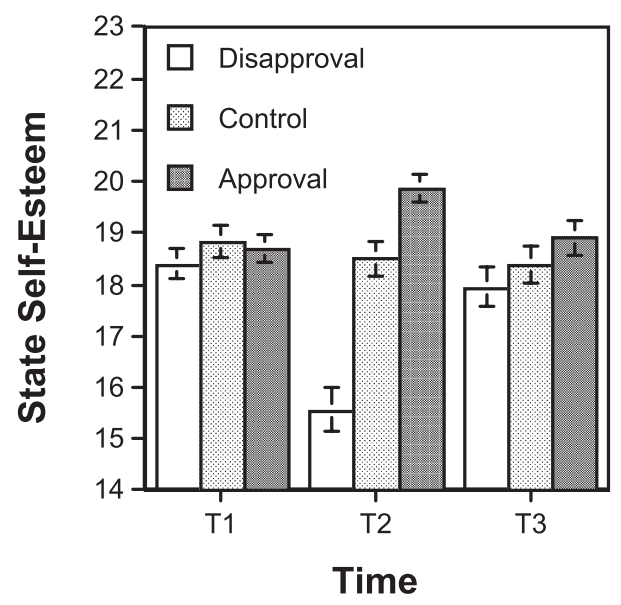

Figure 1. State self-esteem means at T1 (baseline), T2 (after jury feedback), and T3 (after viewing the individual judges' feedback) for children in the disapproval, control, and approval conditions. Note. Error bars represent $\pm 1 S E$. who showed statistically significant intraindividual change in state self-esteem following the manipulated jury feedback from those who did not. The $\mathrm{RC}$ index provides a psychometrically sound criterion for how much change should occur between two assessments to reflect more than just random variation of an imprecise measurement instrument. Thus, it provides an ideal method to distinguish genuine self-esteem change from artifactual change (Jacobson \& Truax, 1991). Using this stringent criterion, in the disapproval condition 31 children (29\%) showed a significant decrease in state self-esteem. In the control condition, 4 children (4\%) showed a significant increase in state self-esteem, whereas 7 children $(6 \%)$ showed a significant decrease in state self-esteem. In the approval condition, 15 participants $(14 \%)$ showed a significant increase in state self-esteem. Thus, in our findings substantial minorities of children who experienced peer approval or disapproval showed genuine intraindividual change in state self-esteem.

We predicted that children who showed genuine decreases in state self-esteem following disapproval would be high in narcissism but would not differ from their less reactive counterparts in self-perceived social acceptance and peer-perceived social preference. The results confirmed our expectation. An ANOVA showed that disapproved children who showed significant decreases in state selfesteem (i.e., decreases that exceeded the RC cutoff) were significantly more narcissistic $(M=10.71$, $S D=6.04)$ than disapproved children who showed no significant decreases in state self-esteem $(M=7.74, \quad S D=4.65), \quad F(1,106)=7.54, p<.01$, $d=0.53$. Both groups did not differ in self-perceived social acceptance $(p>.60)$ or in peer-perceived social preference $(p>.47)$. Similar effects were explored in the approval condition, by testing whether children who showed genuine increases in state self-esteem following approval would be high in narcissism. This was not the case. Narcissism scores were not significantly higher in approved children who showed significant increases in state self-esteem $(M=9.40, S D=5.26)$ than in approved children who showed no significant increases in state self-esteem $(M=8.59, \quad S D=4.30), \quad F(1$, $108)=0.43, p>.51, d=0.13$. Both groups did also not differ in self-perceived social acceptance $(p>.36)$ and peer-perceived social preference $(p>$.97). Thus, narcissism can be considered a specific but asymmetric moderator of children's interpersonal state self-esteem reactivity, such that it is associated with increased reactivity following negative, but not positive social feedback. 
Interpersonal regulation of state self-esteem. Based on sociometer theory, we predicted that peer appraisals should also influence the regulation of disapproved children's lowered state self-esteem. Specifically, positive feedback from perceived popular peers was predicted to have strong regulatory effects (Adler \& Adler, 1998; Hawley et al., 2002; LaFontana \& Cillessen, 2002). Data were analyzed using hierarchical regression analysis. The dependent variable was residualized state self-esteem change from T2 to T3. Residualized state selfesteem change from T1 to T2 was entered as control variable in Step 1. This statistical approach allowed us to examine regulatory change in state selfesteem (from T2 to T3) above and beyond the change that could simply be predicted from prior modulatory change in state self-esteem (from T1 to T2). The main effects for time spent viewing positive feedback from perceived popular judges and RC (i.e., a significant decrease) in state self-esteem from $\mathrm{T} 1$ to $\mathrm{T} 2(n o=0$, yes $=1)$ were entered in Step 2. The two-way interaction was entered in Step 3.

The results of this hierarchical regression analysis are presented in Table 2. In Step 2 of the analysis, disapproved children showed more recovery of state self-esteem the more time they spent viewing positive feedback from perceived popular judges, $t(104)=3.89, p<.001, b=0.39, \beta=.36$. This effect, however, was qualified by its significant interaction with RC in state self-esteem from T1 to T2 in Step $3, t(103)=2.78, p<.01, b=0.58, \beta=.29$. Despite the relatively small sample size of this group, a large and significant effect was found for disapproved children who significantly decreased in state self-esteem from $\mathrm{T} 1$ to $\mathrm{T} 2$. These children showed sharp increases in state self-esteem the more time they spent viewing positive feedback from perceived popular judges, $t(28)=4.07$,

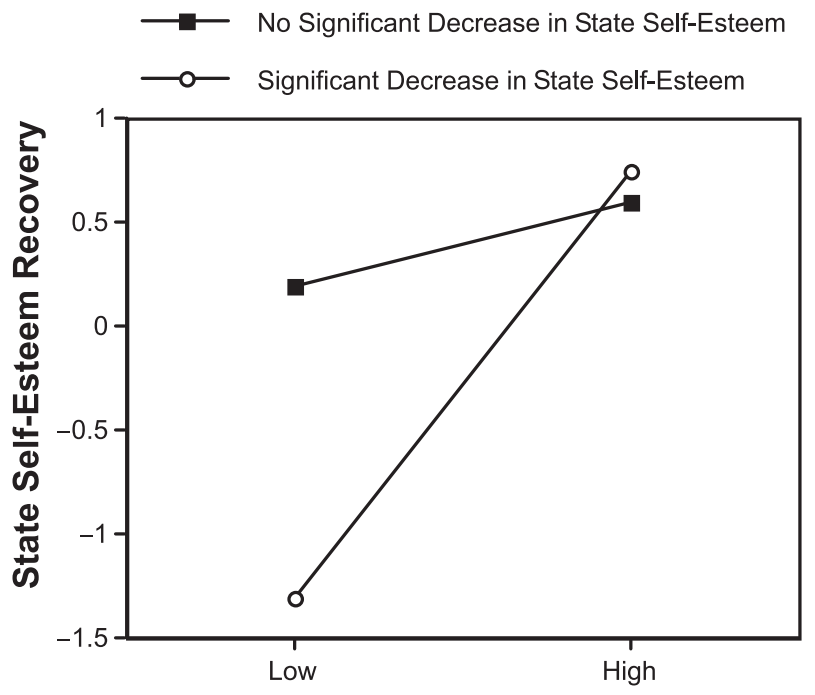

Viewing Time

Figure 2. Relation between time spent viewing positive feedback from perceived popular judges and state self-esteem recovery for disapproved children who did or did not show a significant decrease in state self-esteem following the jury feedback.

$p<.001, b=0.81, \beta=.57$. This relation was not significant for disapproved children who did not significantly decrease in state self-esteem, $t(74)=$ $1.52, p>.13, b=0.17, \beta=.18$ (see Figure 2). Thus, these findings show that attending to positive feedback from perceived popular peers may help in regulating one's lowered state self-esteem, especially among children who experience marked state self-esteem losses.

To test the specificity of this regulatory effect of positive feedback from perceived popular judges, we conducted a series of three similar regression analyses for the other three types of feedback (i.e., positive feedback from unpopular judges, negative

Table 2

Results of Hierarchical Regression Analysis of Residualized State Self-Esteem Change From T1 to T2, the Time Children Spent Viewing Positive Feedback From Perceived Popular Judges, and Reliable Change in State Self-Esteem From T1 to T2 (No =0, Yes = 1) on Residualized State Self-Esteem Change From $\mathrm{T} 2$ to $\mathrm{T} 3$

\begin{tabular}{|c|c|c|c|c|c|}
\hline Step no. & Variable & $t$ & $p$ value & $b(S E)$ & $\beta$ \\
\hline Step 1 & Residualized state self-esteem change T1-T2 & -1.84 & $>.06$ & $-0.17(0.09)$ & -.18 \\
\hline \multirow[t]{3}{*}{ Step 2} & Residualized state self-esteem change T1-T2 & -2.57 & $<.02$ & $-0.33(0.13)$ & -.35 \\
\hline & Viewing time positive feedback perceived popular judges & 3.89 & $<.001$ & $0.39(0.10)$ & .36 \\
\hline & Reliable change in state self-esteem & -1.24 & $>.21$ & $-0.40(0.32)$ & -.17 \\
\hline \multirow[t]{4}{*}{ Step 3} & Residualized state self-esteem change T1-T2 & -2.45 & $<.02$ & $-0.30(0.12)$ & -.32 \\
\hline & Viewing time positive feedback perceived popular judges & 1.82 & $>.07$ & $0.21(0.12)$ & .19 \\
\hline & Reliable change in state self-esteem & -1.29 & $>.20$ & $-0.40(0.31)$ & -.17 \\
\hline & Viewing Time $\times$ Reliable Change & 2.78 & $<.01$ & $0.58(0.21)$ & .29 \\
\hline
\end{tabular}

Note. $R^{2}=.03$ for Step $1 ; \Delta R^{2}=.13(p<.01)$ for Step $2 ; \Delta R^{2}=.06(p<.01)$ for Step 3 . 
feedback from popular judges, and negative feedback from unpopular judges). No significant effects were found ( $p s>.12$ ). Thus, the extent to which disapproved children recovered from a blow to their state self-esteem was specifically dependent on the extent to which they subsequently spent time viewing positive feedback from perceived popular judges.

If it benefits disapproved children to attend to positive feedback from perceived popular peers, one might wonder whether they also have a preference for attending to this kind of feedback over other types of feedback. Results are presented in Table 3. As expected, disapproved children spent more time viewing positive feedback from perceived popular judges than any other type of feedback ( $p$ s < .0001). Importantly, however, the subset of disapproved children who showed significant decreases in state self-esteem did not spend more time viewing positive feedback from perceived popular judges than did disapproved children who showed no significant decreases in state selfesteem, $F(1,106)=0.04, p>.84, d=0.04$. In addition, both groups showed no different viewing times for any of the other types of feedback ( $p$ s > .44). Thus, although disapproved children were inclined to view positive feedback from perceived popular judges over other types of feedback, we found no evidence that their feedback viewing patterns were associated with the amount of state self-esteem they had lost.

\section{Discussion}

The present experiment found strong support for sociometer theory's core postulate that interper- sonal appraisals can have an immediate, causal effect on state self-esteem. First, we found that both peer approval and disapproval experiences modulate children's state self-esteem. In fact, the effect size for peer approval (i.e., $d=0.84$ ) exceeded Cohen's (1988) conventional value for a "large" effect (i.e., $d=0.80$ ), and the effect size for peer disapproval (i.e., $d=1.29$ ) was even larger. Second, we found that peer appraisals can also function to regulate children's state self-esteem. Specifically, the recovery of disapproved children's state self-esteem was dependent on the amount of time they spent viewing positive feedback from perceived popular peers. In contrast, the amount of time they spent viewing positive feedback from unpopular peers had no impact on their state self-esteem.

These results provide the first empirical evidence that short-term sociometer processes already operate in preadolescence, a time of great concern about others' approval (Damon \& Hart, 1988; Harter, 1999, 2006; Rosenberg, 1979). At this age, children have just acquired the ability to evaluate their global worth as a person. Cognitive advances in the ability to appreciate others' appraisals in this same age period allow interpersonal experiences to have a direct impact on selfesteem (Harter, 1999, 2006). Prior longitudinal research already found that preadolescents' trait self-esteem tends to be influenced by cumulative peer experiences they have had in the past (e.g., Boivin et al., 2001; Ladd \& Troop-Gordon, 2003). Our results show that preadolescents' state selfesteem is a highly dynamic psychological entity that can be immediately reactive to the social context as it currently unfolds.

The present experiment also extends the literature by examining the role of individual differences

Table 3

Time Spent by Disapproved Children on Different Types of Feedback

\begin{tabular}{|c|c|c|c|c|}
\hline \multirow{2}{*}{$\begin{array}{l}\text { Viewing time in seconds } \\
\text { (total viewing time }=300 \mathrm{~s} \text { ) }\end{array}$} & & $\begin{array}{l}\text { All disapproved } \\
\text { children (regardless } \\
\text { of state self-esteem } \\
\text { decrease; } N=108 \text { ) }\end{array}$ & $\begin{array}{l}\text { Disapproved children } \\
\text { showing significant } \\
\text { decrease of state } \\
\text { self-esteem }(N=31)\end{array}$ & $\begin{array}{c}\text { Disapproved children } \\
\text { showing no significant } \\
\text { decrease of state } \\
\text { self-esteem }(N=77)\end{array}$ \\
\hline & Range & $M(S D)$ & $M(S D)$ & $M(S D)$ \\
\hline $\begin{array}{l}\text { Positive feedback from perceived } \\
\text { popular judges }\end{array}$ & $11-252$ & $94(39)$ & $93(40)$ & 95 (39) \\
\hline $\begin{array}{l}\text { Positive feedback from perceived } \\
\text { unpopular judges }\end{array}$ & $0-173$ & $76(31)$ & 79 (35) & 75 (30) \\
\hline $\begin{array}{l}\text { Negative feedback from perceived } \\
\text { popular judges }\end{array}$ & $0-175$ & $66(33)$ & $68(34)$ & $65(33)$ \\
\hline $\begin{array}{l}\text { Negative feedback from perceived } \\
\text { unpopular judges }\end{array}$ & $0-163$ & $63(33)$ & $59(38)$ & $65(31)$ \\
\hline
\end{tabular}


in sociometer processes. Prior research in adults primarily approached sociometer processes as universal (Denissen, Penke, Schmitt, \& Van Aken, 2008; Leary \& Downs, 1995; Leary et al., 1998; but see Srivastava \& Beer, 2005, for a notable exception). In our study, the strength of sociometer effects varied substantially between participants. Only subsets of participants showed significant intra individual change following approval and disapproval when judged by the RC criterion (Christensen \& Mendoza, 1986). It should be emphasized that this criterion is stringent. Still, this finding may raise the question whether sociometer processes are as prevalent in preadolescent children as they are in adults (Leary et al., 2003). For example, one may speculate that although preadolescents typically have acquired the cognitive abilities that allow interpersonal experiences to influence their self-esteem, these abilities are perhaps not yet as fully ingrained and habitually employed as they are later in development. It would be premature to draw such a conclusion based on our findings, but clearly, establishing the generality of sociometer processes in these relatively early stages of development will be an important direction for future research.

We predicted that the strongest sociometer effects would be found among those children who are most concerned about obtaining approval from others. Consistent with that notion, we found that children who showed marked state self-esteem losses following disapproval were high on narcissism - a trait that reflects children's preoccupation with being valued and admired by others (Morf \& Rhodewalt, 2001; Thomaes, Stegge, et al., 2008). Narcissists constantly seek external self-affirmation, possibly in order to create desired self-views or to meet self-evaluative needs (Morf \& Rhodewalt, 2001). Our results suggest that when they do not succeed, they immediately lose state self-esteem. Importantly, the subset of disapproved children who showed marked state self-esteem losses did not differ from others in self-perceived social acceptance and peer-perceived social preference. Thus, consistent with sociometer theory, these results suggest that interpersonal state self-esteem reactivity is most pronounced in children with a heightened need for external validation, and not just a default characteristic of children holding social vulnerabilities.

Perhaps most important was our finding that children's state self-esteem reactivity is influenced not only by the traits of the person being evaluated but also by the traits of the evaluator. In preadolescence, the perceived popularity of peers is a highly salient dimension along which children judge each other. The social power of perceived popular children reaches so far that they can dictate to a large extent what members of a social group are valued and accepted and what members are not (Adler \& Adler, 1998; Hawley et al., 2002; LaFontana \& Cillessen, 2002). In this light, it should come as no surprise that the manipulated popularity of judges who gave positive feedback strongly influenced the extent to which children recovered from prior disapproval. Being approved by a popular peer is significant, because it implicitly conveys the prospect that one is likely to be valued by peers in the future. Being approved by an unpopular peer is much less significant, because it tells little about how one will be valued by peers in the future.

One might be inclined to infer from these findings that disapproved children intentionally sought positive feedback from popular peers in an effort to regulate their lowered self-esteem. Although we did not test children's intentional feedback-seeking strategies (rather, we simply recorded how much time they spent viewing different types of feedback), our findings are inconsistent with such an inference. If disapproved children engaged in intentional self-esteem regulation, one would expect their feedback viewing patterns to depend on the amount of self-esteem they had lost (i.e., one would expect that disapproved children who lost the most self-esteem would spend the most time viewing positive feedback from popular peers). We found no such effect, however. Thus, although attending to positive feedback from popular peers has pronounced self-esteem regulatory effects, we have no indications that disapproved children intentionally seek such feedback to regulate their lowered self-esteem.

\section{Limitations and Future Research}

We have argued that preadolescence is a critical age period for the present experiment. However, our developmental focus limits the ability to make generalizations to children of other ages. Future research should test how interpersonal self-esteem reactivity is influenced by age. For example, is preadolescence indeed the earliest developmental period in which interpersonal self-esteem reactivity can be observed? Is interpersonal self-esteem 
reactivity stronger in developmental periods marked by enhanced interpersonal concern (i.e., preadolescence to middle adolescence) than in other developmental periods? Answers to such questions will help us further understand the interpersonal processes that underlie children's selfesteem development.

Laboratory experiments are the method of choice if one wants to test causal hypotheses about psychological processes. Within the confines of the laboratory, we tried to create an ecological valid peer appraisal procedure by having children interact with (ostensible) peers through the Survivor Game on the Internet. Preadolescents generally are very familiar with using social networking facilities on the Internet to communicate with peers (Valkenburg \& Peter, 2007). Future research is needed to ensure that our findings generalize to other contexts of peer interaction.

It is unlikely that demand characteristics or social desirability effects have influenced the present study findings. No participants expressed suspicion about the study purposes, even when explicitly asked during the debriefing. Moreover, even if some participants had inferred the study purposes, this could not explain the interaction effects we observed (e.g., this could not explain why narcissists would be more prone than their peers to report losing self-esteem following disapproval). Still, future research focusing on more implicit measures of self-esteem (e.g., Greenwald \& Farnham, 2000) may be valuable to corroborate the present study findings.

This study was conducted in the Netherlands. The determinants of self-esteem tend to be very similar across individualistic countries (Markus \& Kitayama, 1991; Oyserman, Coon, \& Kemmelmeier, 2002), suggesting that our findings should be generalizable to children living in North America and most Western European countries. Theoretically, sociometer effects should even be stronger in individuals from collectivistic cultures (e.g., East Asian cultures), who tend to view and evaluate themselves more in terms of their relationships with others (Oyserman et al., 2002). Future research is needed to test this hypothesis.

Our findings are at odds with the single study that examined preadolescents' actually experienced, approval-based self-esteem fluctuations (Nesdale \& Lambert, 2007). One possible explanation is that Nesdale and Lambert (2007) used pretend-play peer appraisal procedures, whereas we led children to believe that they were actually appraised by others. Another possible explanation is that Nesdale and Lambert measured potential change in children's trait self-esteem, not in their state self-esteem. Continued research on the boundary conditions of the sociometer effect will enhance our understanding of the interpersonal nature of children's self-esteem.

\section{Conclusion}

This study found that children's state self-esteem can wax and wane as a function of how much they are liked by peers in the immediate present. Our findings are consistent with the view that state selfesteem functions as a sociometer, a psychological gauge of how much one is currently valued and accepted by others. As is a common characteristic of other human monitoring mechanisms (e.g., hunger), the sensitivity of the sociometer varies substantially between individuals. Just as some individuals experience changes in hunger and satiation more readily than others, some individuals experience changes in state self-esteem more readily than others. Just as some types of food alleviate hungry feelings more effectively than others, some types of social feedback seem to alleviate lowered state self-esteem more effectively than others. When children's interpersonal gauge of state self-esteem is low, praise from popular peers is likely to make it go up again.

\section{References}

Adler, P. A., \& Adler, P. (1998). Peer power: Preadolescent culture and identity. New Brunswick, NJ: Rutgers University Press.

Ainsworth, M. D. S. (1989). Attachments beyond infancy. American Psychologist, 44, 709-716.

American Psychiatric Association. (1994). Diagnostic and statistical manual of mental disorders (4th ed.). Washington, DC: Author.

Baumeister, R. F., \& Leary, M. R. (1995). The need to belong: Desire for interpersonal attachments as a fundamental human motivation. Psychological Bulletin, 117, 497-529.

Baumeister, R. F., \& Vohs, K. D. (2001). Narcissism as addiction to esteem. Psychological Inquiry, 12, 206209.

Boivin, M., Hymel, S., \& Hodges, E. V. E. (2001). Toward a process view of peer rejection and harassment. In J. Juvonen \& S. Graham (Eds.), Peer harassment in school: The plight of the vulnerable and victimized (pp. 265-289). New York: Guilford. 
Burwell, R., \& Shirk, S. (2006). The role of self-worth contingencies in adolescent depression. Journal of Research on Adolescence, 16, 479-490.

Bushman, B. J., \& Baumeister, R. F. (1998). Threatened egotism, narcissism, self-esteem, and direct and displaced aggression: Does self-love or self-hate lead to violence? Journal of Personality and Social Psychology, 75, 219-229.

Christensen, L., \& Mendoza, J. L. (1986). A method of assessing change in a single subject: An alteration of the RC index. Behavior Therapy, 17, 305308.

Cillessen, A. H. N., \& Mayeux, L. (2004). From censure to reinforcement: Developmental changes in the association between aggression and social status. Child Development, 75, 147-163.

Cohen, J. (1988). Statistical power analysis for the behavioral sciences. New York: Academic Press.

Coie, J. D., Dodge, K. A., \& Coppotelli, H. (1982). Dimensions and types of social status: A cross-age perspective. Developmental Psychology, 18, 557-570.

Cole, D. A., Jacquez, F. M., \& Maschman, T. L. (2001). Social origins of depressive cognitions: A longitudinal study of self-perceived competence in children. Cognitive Therapy and Research, 25, 377-395.

Cooley, C. H. (1902). Human nature and the social order. New York: Scribner's.

Crick, N. R., \& Dodge, K. A. (1994). A review and reformulation of social information processing mechanisms in children's social adjustment. Psychological Bulletin, 115, 74-101.

Damon, W., \& Hart, D. (1988). Self-understanding in childhood and adolescence. New York: Cambridge University Press.

Denissen, J. A., Penke, L., Schmitt, D. P., \& Van Aken, M. A. G. (2008). Self-esteem reactions to social interactions: Evidence for sociometer mechanisms across days, people, and nations. Journal of Personality and Social Psychology, 95, 181-196.

Felson, R. B., \& Zielinski, M. A. (1989). Children's selfesteem and parental support. Journal of Marriage and the Family, 51, 727-735.

Greenwald, A. G., \& Farnham, S. D. (2000). Using the Implicit Association Test to measure self-esteem and self-concept. Journal of Personality and Social Psychology, 79, 1022-1038.

Harter, S. (1985). The Self-Perception Profile for Children: Revision of the Perceived Competence Scale for Children (manual). Denver, CO: University of Denver.

Harter, S. (1988). The Self-Perception Profile for Adolescents (manual). Denver, CO: University of Denver.

Harter, S. (1999). The construction of the self: A developmental perspective. New York: Guilford.

Harter, S. (2006). The self. In W. Damon \& R. M. Lerner (Series Eds.) \& N. Eisenberg (Vol. Ed.), Handbook of child psychology: Vol. 3. Social, emotional, and personality development (pp. 505-570). New York: Wiley.
Harter, S., Stocker, C., \& Robinson, N. S. (1996). The perceived directionality of the link between approval and self-worth: The liabilities of a looking glass self-orientation among young adolescents. Journal of Research on Adolescence, 6, 285-308.

Harter, S., \& Whitesell, N. R. (2003). Beyond the debate: Why some adolescents report stable self-worth over time and situation, whereas others report changes in self-worth. Journal of Personality, 71, 1027-1058.

Hawley, P. H., Little, T. D., \& Pasupathi, M. (2002). Winning friends and influencing peers: Strategies of peer influence in late childhood. International Journal of Behavioral Development, 26, 466-473.

Hurley, J. C., \& Underwood, M. K. (2002). Children's understanding of their research rights before and after debriefing: Informed assent, confidentiality, and stopping participation. Child Development, 73, 132-143.

Jacobson, N. S., \& Truax, P. (1991). Clinical significance: A statistical approach to defining meaningful change in psychotherapy research. Journal of Consulting and Clinical Psychology, 59, 12-19.

James, W. (1890). The principles of psychology. New York: Dover.

Johnson, S. L., Meyer, B., Winett, C., \& Small, J. (2000). Social support and self-esteem predict changes in bipolair depression but not mania. Journal of Affective Disorders, 58, 79-86.

Kovacs, M. (1981). Rating scales to assess depression in school-aged children. Acta Paedo Psychiatra, 46, 305315.

Ladd, G., \& Troop-Gordon, W. (2003). The role of chronic peer difficulties in the development of children's psychological adjustment problems. Child Development, 74, 1344-1367.

LaFontana, K. M., \& Cillessen, A. H. N. (2002). Children's perceptions of popular and unpopular peers: A multimethod assessment. Developmental Psychology, 38, 635647.

La Greca, A. M., \& Stone, W. L. (1993). Social Anxiety Scale for Children-Revised: Factor structure and concurrent validity. Journal of Clinical Child Psychology, 22, $17-27$.

Leary, M. R. (1999). Making sense of self-esteem. Current Directions in Psychological Science, 8, 32-35.

Leary, M. R., \& Baumeister, R. F. (2000). The nature and function of self-esteem: Sociometer theory. In M. P. Zanna (Ed.), Advances in experimental social psychology (Vol. 32, pp. 1-62). San Diego: Academic Press.

Leary, M. R., Cottrell, C. A., \& Phillips, M. (2001). Deconfounding the effects of dominance and social acceptance on self-esteem. Journal of Personality and Social Psychology, 81, 898-909.

Leary, M. R., \& Downs, D. L. (1995). Interpersonal functions of the self-esteem motive: The self-esteem system as a sociometer. In M. H. Kernis (Ed.), Efficacy, agency, and self-esteem (pp. 123-144). New York: Plenum. 
Leary, M. R., Gallagher, B., Fors, E., Buttermore, N., Baldwin, E., Kennedy, K., et al. (2003). The invalidity of disclaimers about the effects of social feedback on selfesteem. Personality and Social Psychology Bulletin, 29, 623-636.

Leary, M. R., Haupt, A. L., Strausser, K. S., \& Chokel, J. T. (1998). Calibrating the sociometer: The relationship between interpersonal appraisals and state self-esteem. Journal of Personality and Social Psychology, 74, 12901299.

Leary, M. R., Tambor, E. S., Terdal, S. K., \& Downs, D. L. (1995). Self-esteem as an interpersonal monitor: The sociometer hypothesis. Journal of Personality and Social Psychology, 68, 518-530.

Markus, H. R., \& Kitayama, S. (1991). Culture and the self: Implications for cognition, emotion, and motivation. Psychological Review, 20, 568-579.

Marsh, H. W., Craven, R. G., \& Debus, R. L. (1998). Structure, stability, and development of young children's self-concepts: A multicohort-multioccasion study. Child Development, 69, 1030-1053.

McAninch, C. B., Manolis, M. B., Milich, R., \& Harris, M. J. (1993). Impression formation in children: Influence of gender and expectancy. Child Development, 64, 14921506.

McElhaney, K. B., Antonishak, J., \& Allen, J. P. (2008). "They like me, they like me not": Popularity and adolescents' perceptions of acceptance predicting social functioning over time. Child Development, 79, 720-731.

Mead, G. H. (1934). Mind, self, and society. Chicago: University of Chicago Press.

Morf, C. C., \& Rhodewalt, F. (2001). Unraveling the paradoxes of narcissism: A dynamic self-regulatory processing model. Psychological Inquiry, 12, 177-196.

Mrug, S., \& Hoza, B. (2007). Impression formation and modifiability: Testing a theoretical model. Merrill-Palmer Quarterly, 53, 631-659.

Nesdale, D., \& Lambert, A. (2007). Effects of experimentally manipulated peer group rejection on children's negative affect, self-esteem, and maladaptive social behavior. International Journal of Behavioral Development, 31, 115-122.

Oosterwegel, A., Field, N., Hart, D., \& Anderson, K. (2001). The relation of self-esteem variability to emotion variability, mood, personality traits, and depressive tendencies. Journal of Personality, 69, 689-708.

Oyserman, D., Coon, H. M., \& Kemmelmeier, M. (2002). Rethinking individualism and collectivism: Evaluation of theoretical assumptions and meta-analyses. Psychological Bulletin, 128, 3-72.

Patterson, C. J., Kupersmidt, J. B., \& Griesler, P. C. (1990). Children's perceptions of self and of relationships with others as a function of sociometric status. Child Development, 61, 1335-1349.

Raskin, R., \& Terry, H. (1988). A principal-components analysis of the Narcissistic Personality Inventory and further evidence of its construct validation. Journal of Personality and Social Psychology, 54, 890-902.
Reijntjes, A., Dekovic, M., Vermande, M., \& Telch, M. J. (2007). Children's feedback preferences in response to an experimentally manipulated peer evaluation outcome: The role of depressive symptoms. Journal of Abnormal Child Psychology, 35, 497-507.

Reijntjes, A., Stegge, H., Meerum Terwogt, M., Kamphuis, J. H., \& Telch, M. J. (2006). Emotion regulation and its effects on mood improvement in response to an in vivo peer rejection challenge. Emotion, $6,543-552$.

Rhodewalt, F., \& Morf, C. C. (1998). On self-aggrandizement and anger: A temporal analysis of narcissism and affective reactions to success and failure. Journal of Personality and Social Psychology, 74, 672-685.

Robinson, M. D., \& Clore, G. L. (2002). Belief and feeling: Evidence for an accessibility model of emotional selfreport. Psychological Bulletin, 128, 934-960.

Rosenberg, M. (1965). Society and the adolescent self-image. Princeton, NJ: Princeton University Press.

Rosenberg, M. (1979). Conceiving the self. New York: Basic Books.

Rubin, K. H., Bukowski, W. M., \& Parker, J. G. (2006). Peer interactions, relationships, and groups. In W. Damon \& R. M. Lerner (Series Eds.) \& N. Eisenberg (Vol. Ed.), Handbook of child psychology: Vol. 3. Social, emotional, and personality development (pp. 571-645). New York: Wiley.

Rudolph, K. D., Caldwell, M. S., \& Conley, C. S. (2005). Need for approval and children's well-being. Child Development, 76, 309-323.

Saarni, C. (1999). The development of emotional competence. New York: Guilford.

Salmivalli, C., \& Isaacs, J. (2005). Prospective relations among victimization, rejection, friendlessness, and children's self-and peer-perceptions. Child Development, 76, 1161-1171.

Srivastava, S., \& Beer, J. S. (2005). How self-evaluations relate to being liked by others: Integrating sociometer and attachment perspectives. Journal of Personality and Social Psychology, 89, 966-977.

Thomaes, S., Bushman, B. J., Orobio de Castro, B., Cohen, G. L., \& Denissen, J. J. A. (2009). Reducing narcissistic aggression by buttressing self-esteem: An experimental field study. Manuscript submitted for publication.

Thomaes, S., Bushman, B. J., Stegge, H., \& Olthof, T. (2008). Trumping shame by blasts of noise: Narcissism, self-esteem, shame, and aggression in young adolescents. Child Development, 79, 1792-1801.

Thomaes, S., Stegge, H., Bushman, B. J., Olthof, T., \& Denissen, J. (2008). Development and validation of the Childhood Narcissism Scale. Journal of Personality Assessment, 90, 382-391.

Valkenburg, P. M., \& Peter, J. (2007). Preadolescents' and adolescents' online communication and their closeness to friends. Developmental Psychology, 43, 267277.

Veerman, J. W., Straathof, M. A. E., Treffers, P. D. A., Van den Bergh, B. R. H., \& ten Brink, L. T. (1997). Han- 
dleiding Competentiebelevingsschaal voor Kinderen CBSK [Manual for the Dutch version of the Self-perception profile for children]. Lisse, Netherlands: Swets \& Zeitlinger.

\section{Appendix: State Self-Esteem Scale}

1. I am satisfied with myself right now.
2. I feel down on myself right now.*

3. I am proud of myself right now.

4. I am dissatisfied with myself right now.*

5. I feel good about who I am right now.

6. I am disappointed in myself right now.*

Note. Responses are scored using a 5-point scale ranging from 0 (not at all) to 4 (very much). Items marked with an asterisk were reverse scored. 